\title{
VILLAR Diego, Bolivia a vapor. Antropología histórica del barco cauchero (1880-1920)
}

\author{
Pilar García Jordán
}

\section{OpenEdition}

\section{Journals}

Edición electrónica

URL: https://journals.openedition.org/jsa/18739

DOI: $10.4000 /$ jsa. 18739

ISSN: 1957-7842

\section{Editor}

Société des américanistes

\section{Edición impresa}

Fecha de publicación: 15 diciembre 2020

Paginación: 288-295

ISSN: 0037-9174

\section{Referencia electrónica}

Pilar García Jordán, «VILLAR Diego, Bolivia a vapor. Antropología histórica del barco cauchero (1880-1920)», Journal de la Société des américanistes [En línea], 106-2 | 2020, Publicado el 30 diciembre 2020, consultado el 16 septiembre 2022. URL: http://journals.openedition.org/jsa/18739 ; DOI: https:// doi.org/10.4000/jsa.18739

Este documento fue generado automáticamente el 16 septiembre 2022

All rights reserved 


\title{
VILlAR Diego, Bolivia a vapor. Antropología histórica del barco cauchero (1880-1920)
}

\author{
Pilar García Jordán
}

\section{REFERENCIA}

VILLAR Diego, Bolivia a vapor. Antropología histórica del barco cauchero (1880-1920), Editorial El País (Ciencias Sociales e Historia, 47), Santa Cruz de la Sierra, 2020, 228 p., bibliogr., índices, ilustraciones (en blanco y negro), 36 fotografías, 1 mapa.

1 No puede sorprendernos que este libro responda, como dice su autor, a la "nostalgia infantil y por tanto al capricho". De ahí que decida dedicarlo, entre otros tantos navíos célebres, a la Surprise, fragata de la Armada Real Británica, escenario de las aventuras de los amigos Jack Aubrey y Stephen Maturin con el telón de fondo de las guerras napoleónicas narradas por Patrick O'Brian; al Duncan, protagonista tecnológico del viaje alrededor del mundo emprendido por el escocés Lord Edward Glenarvan, su esposa, los hijos del capitán Grant y el geógrafo Jacques Paganel para rescatar al náufrago Grant relatado por Julio Verne; al Aurora de Tintín y del capitán Haddock, protagonistas de las historietas de Hergé; o a la Nellie, cuyos pasajeros, mientras esperan en el Támesis el momento oportuno para hacerse a la mar, escuchan el relato que hace Marlow, alter ego de Joseph Conrad, de su famoso viaje al corazón de las tinieblas. Se trata de una dedicatoria entonces a barcos diversos cuyos pasajeros viven emocionantes aventuras, la mayoría de las cuales transcurren en el siglo xIx.

2 Y no es una sorpresa, tampoco, que tales obras de ficción hayan inspirado al autor de la obra aquí reseñada, en la que el protagonista indiscutible es el barco, básicamente el que navega a vapor, entendido como "brazo técnico de la modernidad capitalista" (p. 17). El objetivo de Villar es analizar el barco como "hecho social total", lo que le lleva a estudiar sus condiciones materiales, sociales e ideológicas para bosquejar una 
especie de "lectura antropológica del barco de vapor, de su gente y de su contexto" (p. 21). Este contexto preciso es la explotación gomera en la Amazonía boliviana en el período 1880-1920, y de ahí el título del libro. Aunque su autor señala que no está especialmente interesado en tratar las características técnicas del barco, su papel como instrumento del mercado, o su carácter simbólico como icono de la civilización y del progreso, entre otras cuestiones, lo cierto es que todas ellas son abordadas con mayor o menor relevancia a lo largo del trabajo.

3 Con todo, desde mi punto de vista, la especificidad y relevancia del libro viene dada, en primer lugar y fundamentalmente, por la excelente lectura y disección que hace Villar de las fuentes utilizadas, que no son otras que las proporcionadas básicamente por exploradores, misioneros, científicos, empresarios, militares y políticos, europeos en su mayoría, norteamericanos y bolivianos ${ }^{1}$. Fuentes que son interpeladas a partir de supuestos teóricos de Pratt, Simondon, Barthes y Foucault entre los autores más relevantes, contando además con el apoyo de una extensa bibliografía; y en segundo lugar, por la estructura narrativa escogida, en la que, tras la introducción, a lo largo de los cuatro capítulos de la obra y el epílogo final, el autor articula su respuesta en torno del fenómeno de "la experiencia del barco de vapor en el boom del caucho" (p. 24).

Es la introducción, justamente, la que nos proporciona las informaciones más significativas sobre la incorporación del vapor a la navegación fluvial y marítima, que otorga a Gran Bretaña el claro predominio del mar en el siglo XIX, tanto en términos militares como económicos. Un vapor que a su vez se hará progresivamente presente en los ríos amazónicos, primero en Brasil, poco después en Perú y Bolivia, seguidos a considerable distancia por Ecuador, Colombia y Venezuela; un vapor unido inexorablemente, en este caso, a la explotación de la goma en sus diversas variedades, y que en el caso boliviano crecerá de manera exponencial a partir de 1880 tras el descubrimiento por Edwin Heath de la conexión entre los ríos Beni y Mamoré, lo que permitirá la mejor y más rápida comunicación con el Madeira, el Amazonas y el Atlántico, facilitando por tanto la explotación de los extensos gomales existentes en los ríos Orthon, Tahuamanu, Manuripi, Acre, etc.

Entrando ya en materia, el papel del barco de vapor en la Amazonía boliviana, el primer capítulo titulado Argonautas del río oriental se inicia con el apartado "Rafael Paz se ahoga", en el que se registra el testimonio dejado por el franciscano Nicolás Armentia sobre su viaje exploratorio por el Madre de Dios en 1884, realizado a bordo del batelón del cauchero Claussen. La embarcación encalla en diversos bancos de arena, en uno de los cuales, tratando de resolver el problema, el remero Rafael Paz perece ahogado; tras la consternación general el viaje prosigue. Es a partir de esta anécdota puntual que Villar se interroga sobre la conexión existente entre la lógica del extractivismo gomero y la práctica cotidiana de la navegación fluvial para señalar, bajo la "Tetralogía del remo", los aspectos técnicos relativos a las embarcaciones que navegaban por entonces los ríos amazónicos bolivianos: canoa, montería, garitea y batelón. Y, a modo de las muñecas rusas, cada apartado se abre al siguiente para recrear la dificultad y peligrosidad de la navegación fluvial derivada del escaso calado de los ríos, de la imprevisibilidad de las corrientes de cieno, de las cambiantes cachuelas (rápidos o cascadas) que en ocasiones exigen transportar la carga a pie para aligerar el peso de la embarcación y así proseguir el viaje, de las enfermedades (disentería, beri-beri y, sobre todo, la malaria), y de los ataques de aquellos que las fuentes llaman "salvajes". 
6 Es a partir de los testimonios en torno a la navegación a remo que el autor reflexiona sobre la geografía de la región; sobre la diversidad étnica en ella, representada en los testimonios que diferencian a los indígenas "civilizados" que tras haber sido reducidos en misiones se adaptan a "las demandas de la nación y el mercado", de los indígenas "salvajes" que "carecen de cultura del trabajo, de civilidad o de capacidad para generar excedentes" (p. 50); sobre el papel desempeñado en el barco por el capitán, los mozos y, fundamentalmente, los remeros, menores de edad en muchos casos -cuyos salarios se incrementan con el auge gomero cuando pasan a ser un recurso escaso a partir de la década de 1860-, muchos de los cuales perecen en el río a consecuencia de accidentes, epidemias y explosiones de violencia por parte de los empresarios y comerciantes gomeros; análisis de Villar que alcanzan, finalmente, a la gestión que estos últimos hacen de la empresa cauchera, y de la complicidad entre autoridades y empresarios locales ante la notoria impotencia de las autoridades prefecturales.

7 Pese al incremento progresivo del vapor en los ríos amazónicos bolivianos en el último cuarto del siglo xIX, el "país de los remeros" de Gabriel René Moreno no desaparece, afirmación con la que el autor concluye el primer capítulo y aborda el segundo bajo el explicativo título de El vapor y el caucho. Villar parte en esta ocasión de "La última escena de Fitzcarraldo", que narra el encuentro del "rey del caucho" con su colega boliviano Antonio Vaca Díez; ambos deciden explorar en 1897 las cuencas del Urubamba y el Ucayali con el vapor Adolfito contra el parecer de los prácticos locales, que sugieren hacerlo en barcos a remo. La pérdida del control de la nave por el capitán alemán contratado por Vaca Díez cerca de la cachuela Pucallpa provoca el naufragio del barco y la muerte de la mayoría de sus tripulantes, incluidos los dos empresarios caucheros, dejando a Nicolás Suárez, socio y principal competidor de aquel, el campo libre para sus proyectos. $\mathrm{Y}$ es a partir de este punto que Villar aborda algunas de las cuestiones derivadas del papel desempeñado por los ríos como "puerta de entrada natural del progreso, la civilización y el libre comercio" y, por ende, la utilización del barco a vapor como la solución técnica más eficaz y económica para el progreso de la Amazonía; y ello se desarrolla en el contexto de una relación neocolonial con las metrópolis europeas y estadounidense que lleva al Estado boliviano a firmar contratos con empresarios extranjeros, como el firmado con el coronel church para la creación de la Compañía Nacional de Navegación Boliviana (1868), que acabará en fracaso.

Estas reflexiones preceden al análisis, primero, de la actividad desarrollada por Nicolás Suárez quien, tras el descubrimiento de Heath, intuye tanto el potencial económico de la confluencia entre el Beni y Madre de Dios, donde surgirá la ciudad de Riberalta, como el lugar estratégico que será su futura base de operaciones, Cachuela Esperanza; será a partir de esta base que Suárez construirá su imperio cauchero en el que controlará todo el proceso desde la recolección de la goma hasta su colocación en los mercados exteriores. Pero, además, desde allí gestionará la aparición de los primeros barcos de vapor en la segunda mitad de la década de 1880, construidos inicialmente en Europa y que, en general, llegan desmontados a Bolivia, donde serán ensamblados en astilleros surgidos en Riberalta, Villa Bella o Guyaramerín, algunos de los cuales figuran tanto en fotografías de época como en imágenes actuales incluidas en el libro.

Se trata de barcos con heterogéneas denominaciones cuya presencia se impone en los ríos bolivianos dada la "eficiencia" del vapor que, no obstante, como señala el autor a partir de las fuentes, se ve desafiada tanto por la geografía amazónica como por la ausencia de mapas y de cartas fluviales actualizadas. Estos son los motivos por los 
cuales, por un lado, las canoas, monterías y batelones continúan surcando los ríos amazónicos y, por otro lado, resulta igualmente fundamental el concurso de tripulaciones -étnicamente heterogéneas aunque con importante presencia indígenacon un conocimiento práctico de las cuencas fluviales. Villar se interroga sobre la repercusión del vapor en el boom gomero y sostiene que, mientras algunas fuentes se inclinan por el "determinismo tecnológico", según el cual el vapor representa la modernidad y es el único medio de lograr aquello que Becerra Casanovas denominó "la reducción del salvajismo a la vida social" (p. 105); otros testimonios, entre los cuales se enrola, señalan que la colonización y la explotación de las gomas se vieron facilitadas por las lanchas de vapor, pero niegan que estas fueran la condición necesaria para el desarrollo de procesos que, quizá en forma más lenta, hubieran tenido lugar igualmente con los barcos de remos.

En El viaje de vapor, título del tercer capítulo, Villar nos acerca a la experiencia cotidiana del viaje en los ríos amazónicos que, para algunas fuentes, resulta algo confortable. El vapor es presentado como icono de progreso y modernidad, símbolo de lujo, de prestigio y de estatus social, y así aparece, entre otros, en los testimonios del español Ciro Bayo o de la británica Lizzie Hessel. Sin embargo, en la mayor parte de las fuentes el relato que se hace de la vida en el barco distaba mucho de esa imagen idílica. Las diferencias, según el autor, están directamente vinculadas tanto al tamaño y características de la nave como a la clase de pasajeros (primera, segunda y tercera clase). Siempre a partir de las fuentes -siendo muy recurrente en este capítulo el relato del suizo Ernst Leutenegger- ${ }^{2}$, señala Villar que son escasos los barcos que disponen de comodidades tales como cabinas y baños, y en los cuales realmente se puede disfrutar de una apreciable oferta culinaria; por el contrario, son mayoría aquellos otros en los que los pasajeros conviven con la tripulación, la carga y los animales (el transporte y la comercialización de estos era un buen negocio para los capitanes y dueños del barco), y sometidos a una dieta de panecillos de harina, arroz con charque, plátanos y la única bebida asequible económicamente, que era el agua turbia del río. Además de las comodidades del viaje, o más bien de su ausencia, los relatos mencionan el tedio y la rutina, alterados esporádicamente por el encuentro con otros vapores y diversos pasatiempos.

11 Sin embargo, más allá de estas narraciones, Villar muestra a partir de varios testimonios que el viaje escenifica una representación de la geografía amazónica "en la cual el pasajero procesa la alteridad y domestica el paisaje al encuadrarlo, regularlo o disciplinarlo de forma moralmente aceptable" (p.133). En algunos casos, las fuentes testimonian un paisaje centrado en la geografía amazónica, la flora y la fauna, así como determinados aspectos de la economía y sociedad de las barracas; en otros casos, los relatos son, según el autor, más "humboldtianos", y en ellos coexisten la descripción objetiva con la apreciación subjetiva, mostrando entonces que varias de las narraciones mencionadas son tanto literatura científica como sentimental (Pratt 2010 [1992], capítulos 2 y 3 respectivamente).

12 No obstante, un elemento presente en casi toda la narrativa fluvial es la oposición entre la "identidad de la civilización y la alteridad de la barbarie" (p. 140), que es mucho más nítida y marcada en el barco a vapor que en el batelón. Igualmente, las necesarias paradas en las barracas gomeras para, entre otras cuestiones, aprovisionarse de leña con la que alimentar el vapor, van integrando gradualmente la geografía gomera a la experiencia del viajero y, con ello, "la jungla se percibe como un paisaje visual que pasa 
de largo pero a la vez solo puede aprehenderse y domesticarse gracias a la maquinaria omnipresente de la industria gomera" (p. 144).

Una valoración integral de la navegación a vapor exige considerar también, en el contexto fronterizo de la mayoría de los ríos gomeros, la defensa de la soberanía boliviana en la región, como asimismo la propia guerra, problemáticas centrales del cuarto capítulo titulado Vapor, guerra y nación. Desde el primer apartado, "Aventuras del capitán Posnansky", es claro que el hilo conductor de la narración será la experiencia de este joven ingeniero austriaco que en 1896 viaja a Sudamérica y llega, en pleno boom cauchero, a la región del Acre con su lancha a vapor Anni, cuyas características la hacen particularmente eficaz para navegar por la siempre difícil hidrografía selvática; allí se dedica al flete de goma y mercancías entre el Acre y la ciudad de Manaos. Ello acaece justamente cuando la región se encuentra en un litigio fronterizo entre Bolivia y Brasil que, por razones explicadas en una abundante bibliografía, se resuelve solo tras la guerra que enfrenta a ambos países y que concluye con la derrota del primero en 1903.

La coyuntura es propicia, aparentemente, para el surgimiento del fervor nacionalista en defensa de la región aunque, en la práctica, la mayoría de la población boliviana es ajena tanto al conflicto como a la cesión obligada de casi $200000 \mathrm{~km}^{2}$ al Brasil ${ }^{3}$. Con todo, lo que aquí interesa señalar es que el conflicto militar permite a Villar darle protagonismo a dos actores privados en esta guerra: uno es Posnansky, quien pone al servicio de la causa boliviana su persona y su embarcación, rebautizada con el significativo nombre de Iris $^{4}$, y que parece ser el único barco que se ve envuelto en escaramuzas varias; y el otro es el propio Nicolás Suárez, quien además de poner su flotilla de vapores a disposición del esfuerzo bélico nacional organiza una columna terrestre para apoyar a las tropas que, enviadas por el gobierno de Pando, han sido sitiadas en Puerto Acre ${ }^{5}$. Conflicto militar en el que, como bien nota Villar, los vapores son una pieza fundamental de la logística boliviana (transporte de fuerzas militares, provisiones, evacuación de heridos y enfermos, correo, reconocimiento). Es así como, bajo el título de "La guerra como continuación de la economía por otros medios", el apartado más extenso del libro, el autor sostiene a partir de las fuentes, y en particular de los relatos de Posnansky, que el conflicto acreano es más bien "una guerra tercerizada, privatizada, que no llega a desligarse en ningún momento de una lógica mercantil", pues a lo largo del conflicto la explotación gomera continúa ${ }^{6}$. Aún más, una cuestión fundamental subyacente tanto en los relatos del austriaco como del propio Suárez, más allá de su diversidad, es la necesidad de reconocimiento moral y de compensación económica por los servicios prestados por ambos a Bolivia, revelando así "la total dependencia boliviana de los actores privados a la hora de defender las fronteras nacionales" (p. 177).

Llegando al epílogo, es claro que el vapor, icono de civilización y progreso, constituye un eslabón que forma parte de un contexto singular que involucra aspectos tales como las características de la red fluvial, la estructura de la industria gomera, la política nacional y regional, o los propios actores sociales involucrados. Aspectos todos ellos que Villar consigue diseccionar en la gran cantidad de fuentes que utiliza, hasta el punto que parece no haber dejado ningún resquicio bibliográfico por analizar, razón por la cual me parece que esta obra es una muy útil y sugerente contribución a la recreación de la realidad amazónica durante el boom cauchero. Además, a mi juicio, el análisis realizado por el autor permite formular, entre otras, algunas preguntas significativas sobre la gestión del territorio y la explotación de los recursos naturales 
en beneficio de toda la sociedad y no de unos pocos. Concluye Villar que en la memoria colectiva actual el vapor "es patrimonializado como símbolo prestigioso de la historia regional", pero es también claro que la historia observada a través del vapor es una historia de "ambigüedades, dilemas y paradojas" (p. 211-212) de la que, desde mi punto de vista, los grupos dirigentes que han gestionado la res pública en Bolivia y en la región amazónica no salen bien parados.

\section{BIBLIOGRAFÍA}

CóRDOBA Lorena (ed.)

2015 Dos suizos en la selva. Historias del auge cauchero en el Oriente boliviano, SOLIDAR Suiza/CIHA, Santa Cruz de la Sierra.

GUITERAS MOMBIOLA Anna

2018 "Estudio introductorio. Nicolás Suárez, pionero y patriota en los confines de la Amazonía boliviana", in Nicolás Suárez, Anotaciones y documentos sobre la campaña del Alto Acre 1902-1903, Plural/Biblioteca del Bicentenario de Bolivia, La Paz.

PRATT Mary Louise

2010 [1992] Ojos Imperiales. Literatura de viajes y transculturación, Fondo de Cultura Económica, México.

\section{NOTAS}

1. Fuentes que, coincido con el autor, abordan en forma más o menos realista el espacio socioeconómico y cultural conformado por la explotación gomera en la Amazonía boliviana y que presentan una calidad dispar: así, por un lado, hay relatos que registran detalladamente todos los aspectos vinculados al viaje, empezando por las características técnicas del barco, su carga, tripulación y pasajeros, el desplazamiento por las barracas gomeras, los aspectos relevantes de la navegación por las cambiantes condiciones de navegabilidad de los ríos, el paisaje amazónico y hasta el universo social conformado por los actores de la explotación gomera (Armentia, Bayo, Suárez, Fawcett, Posnansky, del Castillo, Ritz, Leutenegger); por otro lado, narraciones que solo tangencialmente se ocupan del barco pero que a través de informaciones puntuales y aun de silencios permiten reconstruir la realidad retratada desde el barco (entre otros, los relatos de Pando, Ballivián, o Keller). Muchas de estas fuentes corresponden a la literatura de viajes, razón por la cual me parece pertinente señalar que este tipo de relatos responde a la necesidad que los "centros imperiales del poder" tienen de presentar y de representarse a sí mismos y a los otros (Pratt 2010 [1992], p. 25-26]). Posición esta subyacente en la obra aquí reseñada.

2. El testimonio de Leutenegger recoge sus experiencias como empleado de la empresa cauchera de Nicolás Suárez desde 1906 hasta 1911-1912 y es de una riqueza extraordinaria, tal como muestra la excelente edición que de su obra publicó en 
castellano Lorena Córdoba en 2015. La editora también incluyó en ella el relato de otro cauchero suizo, Franz Ritz, testimonio de la primera estadía de este en la región (1907-1914) como empleado de la firma Braillard. Este último relato es también utilizado por Villar, aunque resulta menos interesante que el firmado por Leutenegger.

3. Es bien sabido que la región, que forma parte de los llamados Orientes bolivianos (Amazonía y Chaco fundamentalmente), mereció escasa sino nula atención en todos los proyectos políticos nacionales desde la independencia y hasta, como mínimo, la década de 1880, salvo por la excepción significativa del gobierno presidido por José Ballivián (1841-1847). Sorprende constatar, cuanto menos desde el punto de vista cultural con todas las implicaciones simbólicas correspondientes, que el fervor nacionalista en Bolivia se concentra aún en la actualidad en la pérdida de su salida al mar, y que prácticamente hayan desaparecido de la memoria colectiva boliviana todas las cesiones territoriales realizadas, por vía diplomática o militar, tanto en la Amazonía como en el Chaco.

4. En la mitología griega Iris es la diosa del arcoíris, encargada de comunicar a los hombres los mensajes de los dioses.

5. Suárez publicó en 1928 sus reflexiones y documentos sobre su participación en la campaña en una obra reeditada recientemente con una excelente introducción de Guiteras Mombiola (2018, p. 13-41).

6. Es evidente, como señala Villar, la simbiosis entre industria gomera y Estado boliviano que se observa tanto en tiempos de paz como de guerra. En el caso específico de Suárez, los relatos e informes sobre el avance de la frontera nororiental muestran al personaje como un "agente civilizador"; por otra parte, estallado el conflicto militar, resulta claro que la protección de la soberanía nacional desplegada por el empresario supone asimismo la seguridad de su imperio económico; es evidente entonces que la resistencia boliviana depende de la estructura logística de la empresa gomera. Simbiosis que recuerda, aunque el conflicto no se produjo en el campo de batalla sino en la arena judicial, lo ocurrido en la década de 1910 en el conocido escándalo del Putumayo en torno a la figura del empresario cauchero Julio César Arana.

\section{AUTORES}

\section{PILAR GARCÍA JORDÁN}

Taller de Estudios e Investigaciones Andino-Amazónicos (TEIAA), Universitat de Barcelona 